\title{
Resistencia y éxodo
}

\author{
Rafael Tarifa Ortiz \\ DAFITS, Universitat Rovira i Virgili \\ senda.2010@hotmail.com
}

Resumen: La Cooperativa Integral Catalana (CIC) es una entidad dedicada a la producción de vida social; en ella, lo político, lo económico y lo cultural se fusionan. Esta asociación biopolítica insertada en el tercer sector se convierte en un recurso eficiente que recoge parte de la indignación popular y le posibilita un camino de transición hacia «otro mundo posible». En su marcha construye un espacio de encuentro que intenta extender un proyecto de liberación de la sociedad capitalista y del Estado: la Revolución Integral. Con ella establece el marco que guía y delimita su acción libertaria, un esfuerzo colectivo y autogestionado dirigido a resistir los embates derivados del dominio de las instituciones estatales y los mercados económicos. Construir, en un contexto de crisis económica, social y política, los cimientos de un nuevo mundo, los lleva a mirar al pasado, a extraer de las anteriores luchas de liberación sus mejores frutos, a apoyarse en la experiencia de las actuales y unir fuerzas en encuentros productivos. Extender y potenciar un proceso revolucionario donde el común desbanque a la propiedad privada o pública es su meta. Para alcanzarla, desarrolla en el camino la infraestructura material e inmaterial que permite zafarse de la red de significados que la sociedad capitalista ha ido tejiendo durante la modernidad: la lucha toma forma de éxodo.

Palabras clave: Cooperativa Integral Catalana; éxodo; resistencia.

Abstract: The Cooperativa Integral Catalana (Catalan Comprehensive Cooperative - CIC) is a social organisation working in the political, economic and cultural spheres. This biopolitical association working in the third sector has become an efficient resource for channelling public anger and enabling a transition towards "another better world". Through its activities it creates a meeting place that aims to spread a Comprehensive Revolution; that is, a project of liberation from capitalist society and the State. The cooperative establishes the framework that guides and delimits its struggle for freedom, a 
collective and self-managed effort aimed at resisting the onslaughts meted out by the ruling state institutions and economic markets. In a context of economic, social and political crisis, the act of constructing the foundations of a new world leads the members of the cooperative to look to the past in order to reaps the best fruits of previous struggles for freedom, to draw on the experiences of current struggles and to unite their efforts in productive encounters. The goal is to spread and strengthen a revolutionary process in which the shared displaces private or public property. To achieve this, it develops the material and immaterial infrastructure that allows it to break loose from the network of meanings that capitalist society has weaved throughout modernity: the struggle is taking the form of an exodus.

Key words: Cooperativa Integral Catalana; exodus; resistance.

\section{Introducción}

Para la elaboración de este artículo me he basado en el estudio de las publicaciones de los miembros y colectivos que integran la Cooperativa Integral Catalana (CIC) y en el trabajo de campo que he ido desarrollando a lo largo del periodo de doctorado en esta entidad. Este artículo es un breve análisis del planteamiento ideológico de la CIC como plataforma antisistema. Su objetivo es visibilizar el vínculo cognitivo existente entre la entidad y el movimiento antiglobalización.

Para tal fin se ha construido un relato contextualizado y comprensivo que, aunque reducido, permite avanzar hacia el conocimiento de la misma. Redactado con una visión emic (desde la perspectiva de los activistas de la CIC), intenta interpretar el sentido de la movilización que protagoniza la entidad, decodificando su discurso para aproximarnos al mundo de representaciones simbólicas de los actores. Es decir, he descrito la acción colectiva de la entidad con sus propias estructuras de significación.

No habría que confundir este tipo de aproximación con una defensa o un posicionamiento ideológico que impida analizar con la distancia necesaria la entidad. Lograr el acceso al mundo conceptual de los activistas me ha permitido interpretar plausiblemente su acción colectiva y trasladar este conocimiento al resto de la comunidad académica. Sigo, por tanto, la orientación de Geertz 
cuando en su obra La interpretación de las culturas (2011) menciona que para desarrollar un análisis antropológico nuestras descripciones deben orientarse en función del actor, en intentar captar el conjunto de valores y principios que sostienen su acción apoyándonos en su propio discurso. Mi descripción será una interpretación, un intento de comprensión de su cultura donde no se establecen juicios de valor. No es, por tanto, una mera reproducción acrítica de la acción colectiva que protagoniza la entidad:

Comprender la cultura de un pueblo supone captar su carácter normal sin reducir su particularidad [...]. Dicha comprensión los hace accesibles, los coloca en el marco de sus propias trivialidades y disipa su opacidad. [... ] Nada es más necesario para comprender lo que es la interpretación antropológica y hasta qué punto es interpretación que una comprensión exacta de lo que significa $-\mathrm{y}$ de lo que no significa - afirmar que nuestras formulaciones sobre sistemas simbólicos de otros pueblos deben orientarse en función del actor. Lo cual significa que las descripciones de la cultura de beréberes, judíos o franceses deben encararse atendiendo a los valores que imaginamos que beréberes, judíos o franceses asignan a las cosas, atendiendo a las fórmulas que ellos usan para definir lo que les sucede. Lo que no significa es que tales descripciones sean ellas mismas beréberes, judías o francesas, es decir, parte de la realidad que están describiendo; son antropológicas pues son parte de un sistema en desarrollo de análisis científico. Deben elaborarse atendiendo a las interpretaciones que hacen de su experiencia personas pertenecientes a un grupo particular, porque son descripciones, según ellas mismas declaran, de tales interpretaciones; $y$ son antropológicas porque son en verdad antropólogos quienes las elaboran (Geertz, 2011: 29-28).

En la misma línea, siguiendo la recomendación metodológica en lo relativo al estudio de los movimientos sociales del sociólogo Manuel Castells (2013), he considerado que estos sistemas de acción se definen en función de sus prácticas, especialmente de las discursivas. Y que para establecer una relación entre los distintos movimientos es imprescindible atender a las mismas. Desde esta óptica, una investigación que asuma este reto deberá centrarse en ellas, profundizando en los valores que las sostienen y en los principios que las rigen. Además de intentar contextualizar la acción colectiva de los movimientos y relacionarlos con los procesos sociales que inciden en ella: 
En primer lugar, los movimientos sociales han de comprenderse en sus propios términos: a saber, son lo que dicen ser. Sus prácticas (y sobre todo sus prácticas discursivas) son su autodefinición. [...] Una operación de investigación diferente y necesaria es establecer la relación entre los movimientos, según los definen sus prácticas, sus valores y sus discursos, y los procesos sociales a los que parecen estar asociados (Castells, 2013: 102-103).

A lo largo del artículo podremos observar como el discurso generado desde la entidad encaja y se integra en el discurso en red del movimiento de justicia global. He seleccionado para visibilizar esta relación el marco conceptual que reúne la obra conjunta de dos referentes internacionales clave del movimiento global de resistencia contra el neoliberalismo: Michael Hardt y Antonio Negri. Sus aportaciones son una muestra significativa de ese discurso en red que construye el movimiento antiglobalización. Aquí servirán para destacar las semejanzas entre el esquema de interpretación de la CIC y el del movimiento antiglobalización, cómo esta relación de afinidad posibilita su confluencia:

Como evolución o como ruptura con respecto a estos nuevos movimientos sociales, [...] los nuevos movimientos globales 'democratizan radicalmente' sus formas de actuar. Manejarán un internacionalismo que busca confluencias estables y heterogéneas [...]. Se tenderá a concatenar discursos que tendían a aparecer tematizados por los nuevos movimientos sociales (militarismo, patriarcado, medioambiente, autonomía) o por el movimiento obrero (relaciones capital-trabajo). [...] Así, de las coordinaciones en red pasamos a la difusión de discursos en red. Estos discursos no son una simple agregación de demandas. Tienen en el marco de democracia radical su asiento, [... enfatizan la participación sobre la estructuración o representación social, los procesos abiertos sobre los proyectos totales, la horizontalidad y la vinculación sobre la organización vertical, el cuestionamiento concreto y constructivo sobre la idealización de una universal certeza (Calle, 2005: 25-26).

Me apoyo en la doctrina de Hardt y Negri por dos motivos. En primer lugar, nos ofrece la oportunidad de enmarcar globalmente la acción colectiva de la entidad. A su vez, nos facilita comprender que esta se dirige a la construcción y extensión de un proyecto de transformación social radical. Concretando, con su marco conceptual podremos apreciar que las prácticas, valores y discursos que se dan en la entidad están asociados a los que construye, defiende y desarrolla el movimiento antiglobalización. Contrastar las prácticas discursivas de 
la CIC con la filosofía de la liberación de Hardt y Negri posibilita entender por qué esta entidad se constituye en un nodo más de la compleja estructura reticular del sistema de acción global que hace frente a la ola neoliberal.

En relación con los textos de la CIC que aparecen en este artículo he de mencionar que su selección deriva del trabajo de campo desarrollado en la entidad. He optado por citar fragmentos de sus publicaciones y no hacer uso del material recogido durante las entrevistas. El motivo de esta elección es que estos condensan su proyecto y ayudan a esbozar el marco de referencia de la entidad. Estas publicaciones vienen a construir su discurso colectivo, un relato que refleja fielmente y sin distorsiones su proyecto. Compartir con los activistas su experiencia, formar parte de la estructura de la CIC, me ha ayudado a seleccionar los textos de mayor interés para el tema que aquí se aborda. No intento resaltar la labor individual o la visión particular de ciertos miembros que, por su posición, destacan en la entidad, sino captar el significado del proyecto colectivo de la CIC. Y este se expresa explícitamente en los textos seleccionados. Es su voz colectiva, el discurso consensuado, o al menos mínimamente compartido, el que utilizo para analizar la movilización que intenta impulsar la entidad como iniciativa política.

Aclarado el enfoque metodológico y la selección de los textos, podríamos definir el proyecto colectivo de esta entidad como una apuesta por el cambio incidiendo en todos los ámbitos de la actividad humana (social, económico, cultural y político). Esta iniciativa puede parecer arriesgada y no exenta de grandes obstáculos: cultura hegemónica contraria a sus postulados; dominio actual del poder económico y político antagonista, etc. No obstante, sus miembros son conscientes de esta situación y eso no les resta energía para poner todos sus recursos en el empeño de dejar de estar «bajo la bota» del poder del capital. La CIC es un espacio para la resistencia e intenta extenderla a todos los niveles posibilitando que su acción colectiva se inserte en el tejido reticular de las rebeldías locales y globales que luchan contra el neoliberalismo.

He dividido este texto en dos apartados. En el primero, proporciono una síntesis de la genealogía del movimiento de resistencia global en nuestro país y una posible taxonomía de sus organizaciones; posteriormente me centro en la acción colectiva de la CIC, en cómo intenta generar un nuevo marco de referencia y se conecta a la lucha global para construir el contrapoder. En el segundo 
apartado, desarrollo brevemente cómo intenta la entidad construir el éxodo de la sociedad del capital, qué quiere dejar atrás y hacia dónde se dirige.

De forma esquemática podríamos definir la Cooperativa Integral Catalana (CIC) como el intento desde la sociedad civil $^{1}$ (sentido restringido) de construir una plataforma que proporcione los instrumentos básicos (asesoría jurídica para la desobediencia civil y fiscal, asistencia financiera, vivienda, comunidades, experiencia activista, etc.) que posibiliten llevar a efecto iniciativas autogestionadas. El objetivo general es que bajo su paraguas legal se extienda de forma organizada una red activista que construya los cimientos de un proyecto holístico de transformación de la sociedad. Para ello, pone a disposición de las personas interesadas un conjunto de herramientas que posibilita el desarrollo de nuevas iniciativas y la continuidad (financiera) del proyecto colectivo de la CIC.

La entidad concibe su proyecto como parte del proceso que acompañará a su colectivo en la transición del sistema económico capitalista, y la actual cultura hegemónica, a una sociedad donde las personas sean las protagonistas de su propio destino en el seno de comunidades autogestionadas. Para este fin han construido un marco de referencia que mantiene la esperanza de la llegada de un nuevo mundo que posibilite la justicia y la fraternidad entre las personas. El proceso de liberación de la CIC corregiría la situación actual concebida como deficitaria en todos los ámbitos (social, económico, político, cultural) y lograría la transición a una nueva sociedad apoyándose en principios y prácticas libertarias (autogestión, solidaridad, apoyo mutuo, sistema asambleario, toma de decisiones por consenso, eliminación del Estado y del mercado capitalista, acción directa, colectivización, etc.).

La CIC propone, potencia y desarrolla una acción colectiva que pretende superar la democracia representativa, concebida esta como la fachada de un sistema oligárquico del que derivan todos los problemas que la ciudadanía padece. Esta forma de gobierno sería sustituida por un modelo de transición que construiría una gobernanza constituida por redes de asambleas populares soberanas (democracia directa). Estas asambleas pondrían en marcha una economía diseñada para satisfacer las necesidades de la población y no los intereses del mercado. Un nuevo sistema político y económico contemplado por sus miembros como la única vía posible para lograr la justicia social y la libertad.

1 Representa una muestra de la nueva economía solidaria impulsada desde el Foro Social Mundial (FSM). 
En su seno se encuentran activistas procedentes de diversos movimientos (decrecimiento, anarquista, neozapatista, okupación, 15M, hacker, queer, economía solidaria, ecologista, etc.) que encuentran en el principio de autogestión y el espacio de protección de la CIC la posibilidad de ir construyendo una red que proporcione la seguridad, estabilidad y flexibilidad suficiente para llevar a cabo acciones colectivas que conduzcan a un nuevo estadio histórico de la lucha social. Esta multiplicidad de singularidades que encontramos en la entidad nos permite visionar los primeros elementos que configuran el carácter reticular que adquiere su estructura y nos da pie a abordar en el siguiente apartado la influencia de las luchas de liberación globales en las locales.

\section{Resistencias}

Tal y como he comentado anteriormente, la obra de Michael Hardt y Antonio Negri constituye un referente básico para la comprensión del movimiento de resistencia global contra el neoliberalismo. Sus libros y artículos posibilitan adentrarnos en el océano de la luchas de liberación desde la óptica activista. Podíamos decir que estos dos intelectuales intentan construir a través de sus obras toda una filosofía de la liberación. Desde una óptica activista derrumban los muros académicos para dotar a las fuerzas que luchan por la transformación social de un vasto arsenal conceptual que pretende actuar como instrumento teórico contra lo que han venido a denominar imperio, una nueva forma global de soberanía compuesta por una serie de organismos nacionales y supranacionales que ejercen el dominio bajo la lógica del capital.

El imperio se caracteriza por la ausencia de fronteras y se presenta como un orden que suspende la historia, un intento de congelar el tiempo en un eterno presente. Su dominio traspasaría todo límite y se extendería a todos los ámbitos de la actividad humana, impactando el mundo social en su totalidad y dando lugar al biopoder ${ }^{2}$. Para hacer frente a esta nueva forma de dominio, las fuerzas de la liberación tampoco deben ser frenadas por fronteras territoriales y limitarse a actuar exclusivamente en áreas concretas, sino que han de extenderse globalmente y construir un contraimperio. La cartografía de proyecto de

2 Michael Foucault creó este neologismo añadiendo el prefijo bio- a poder para caracterizar el conjunto de prácticas empleadas por los Estados modernos para subyugar los cuerpos. Este concepto es reinterpretado por Hardt y Negri: «Una forma de poder que regula la vida social desde su interior, siguiéndola, interpretándola, absorbiéndola y rearticulándola» (Hardt; Negri, 2002: 38). 
liberación todavía no ha sido diseñada y asistimos a encuentros productivos entre una multiplicidad de singularidades en resistencia que habrán de sentar las bases de la nueva revolución.

El proceso de globalización ha socavado las fronteras. Ya no hay límites territoriales efectivos, ni esencias culturales que conservar para mantener intacta la «pureza original» de las naciones y los pueblos. Esta situación, resultado del triunfo y el dominio de las élites económicas y políticas neoliberales tras la caída del muro de Berlín, establece a su vez un entorno propicio para la difusión de las fuerzas de liberación que intentan extenderse globalmente y adecuan su forma y contenido para posibilitar la convergencia entre los distintos movimientos partidarios de la revolución. El contagio del virus de la liberación se extiende paradójicamente gracias a las condiciones impuestas por el triunfo del capital: «Las fronteras de los Estados-nación son cada vez más permeables a toda clase de flujos. Nada puede devolvernos los escudos higiénicos de las fronteras coloniales. La era de la globalización es la era del contagio universal» (Hardt y Negri, 2002: 133).

\subsection{Sin fronteras}

Las culturas, en plural, a saber, los conjuntos de significados que son característicos de un grupo o de un territorio y que se adquieren a través de la vida social no pueden ser concebidas actualmente como contenedores estancos que repelen a modo de barrera las influencias del exterior. Los significados que construimos y sus expresiones reciben el impacto de la creciente interconexión espacial (Hannerz, 1998)._Las ideas y sus concreciones fluyen en un mundo globalizado con rapidez en gran medida favorecidas por las TIC. Los antropólogos han pasado del estudio de lo «exótico» y rural al análisis de los fenómenos transnacionales que se generan en las urbes occidentales; las ciudades se constituyen en sus nuevos observatorios.

El mundo se ha convertido en una caja de resonancia, podemos oír los ecos de una cultura en otra. Lo global se funde con lo particular. La modernidad nos llevó a una etapa donde la interdependencia acaba con la «pureza original y su reino». La hibridación y el mestizaje cultural es una constante, y este fenómeno es válido tanto para la «cultura hegemónica» como para las «culturas de resistencia». Ningún fenómeno «local» puede ser analizado sin tener presente 
la influencia y el impacto que recibe del exterior. Si esta premisa es básica para el conjunto de científicos sociales, aún más para los que se dedican al estudio de los movimientos sociales. No solo han surgido formas de acción locales influidas por movimientos exitosos en sus respectivos ámbitos, sino que están inmersas en un esfuerzo continuo enfocado a generar vínculos globales que les posibiliten su existencia y les permita potenciar sus luchas.

Una muestra evidente la tenemos con el «movimiento de movimientos», la «nube de mosquitos», la extensa y diversa estructura reticular que contiene el conocido mediáticamente como movimiento antiglobalización. Una red global de activistas unidos con un objetivo común: el fin o la reforma (en algunos casos) del sistema cultural, social, económico y político que caracteriza a la sociedad actual, resultado de la extensión del sistema capitalista a la práctica totalidad de los países. Este conjunto multiforme de movimientos se oponen a los componentes del sistema mundo, al capitalismo como sistema económico y al Estado como sistema político (Iglesias, 2008).

El pistoletazo de salida de la carrera hacia la emancipación y la liberación tuvo lugar con el alzamiento el 1 de enero de 1994 del Ejército Zapatista de Liberación Nacional (EZLN). Un levantamiento armado contra el por entonces presidente de México, Carlos Salinas de Gortari. Esta acción y su exitosa difusión gracias a las TIC, una hábil política de comunicación y la acción legitimadora de intelectuales afines, situaría una guerrilla local en el papel de paladín de las causas justas, generando, en un mundo ávido de nuevas utopías y sentido tras la caída del muro de Berlín, un nuevo icono para la izquierda: el subcomandante Marcos. Los posmarxistas reciben como buena nueva el aire fresco procedente de la Selva Lacandona (Chiapas). Respiran aliviados después de atravesar el desierto de la derrota y se unen a la lucha zapatista construyendo redes de solidaridad para su causa. Desde una óptica activista, asistimos al parto transnacional de una nueva revolución que intenta extenderse globalmente bajo formas movimentistas.

La tesis que realizó Pablo Iglesias y que aborda como objeto de estudio esta acción colectiva transnacional nos servirá para ilustrar el proceso de génesis y extensión del proyecto de transformación protagonizado por estos grupos:

El conjunto de colectivos que dieron origen al movimiento global comenzó a coordinarse en las redes de solidaridad del Ejército Zapatista de Liberación 
Nacional de México (EZLN) a partir de 1996, dando origen al grupo Acción Global de los Pueblos (AGP) en 1998, que llevó a cabo el llamamiento a la acción global para responder a las reuniones de la OMC en Seattle y del BM y FMI en Praga. Entre aquellos colectivos radicales estaban los que asumirán después la desobediencia como práctica y discurso. [...] Dentro de esta área de colectivos, la tesis se ocupa específicamente de lo que hemos llamado desobediencia italiana, como conjunto de formas de acción colectiva desarrollado por algunos centros sociales y colectivos de la izquierda postautónoma italiana, así como del intento de adaptación de estas formas de concebir y practicar la desobediencia en Madrid (Iglesias, 2008: 43-44).

$\mathrm{Su}$ trabajo académico nos permite relacionar el movimiento antiglobalización con los colectivos y espacios generados en Italia por el movimiento autónomo ${ }^{3}$, así como la extensión y adaptación en España de las formas de accionar de sus colegas europeos por parte de colectivos de izquierda extraparlamentaria. En él describe cómo el movimiento va creciendo en un proceso que conecta neozapatistas mexicanos con los desobedientes italianos, y estos, a su vez, con los invisibles españoles y el Movimiento de Resistencia Global (MRG), embrión de la antiglobalización en España.

Fuera de nuestras fronteras, Michael Löwy (2004) captará también la importancia del levantamiento del EZLN en el proceso de génesis de un movimiento global que lucha por hacer frente a la ofensiva neoliberal. Esta «nube de mosquitos» constituirá, después del proclamado «fin de la historia» con la caída del Muro de Berlín, el intento de creación de un movimiento que, a falta de sujeto histórico (el proletariado), persigue con la construcción de una red transnacional de movimientos la reformulación del proyecto revolucionario socialista y su sustitución por este entramado movimentista:

Fue en un contexto de derrota y desorientación de la izquierda cuando llegó, como un rayo de luz en la oscuridad, el levantamiento zapatista de 1994. Y en 1996, el Primer Encuentro Intercontinental por la Humanidad y Contra el Neoliberalismo se celebró en las montañas de Chiapas. Este acontecimiento tuvo un impacto mundial y juntó, por primera vez en muchísimos años, a militantes, activistas e intelectuales de diferentes tendencias del Norte y del Sur, de América Latina, Estados Unidos y Europa. De esa reunión salió el

3 Corriente política que parte del marxismo libertario para situarse junto al anarquismo, con el que comparte postulados, en lo que se ha venido denominar socialismo libertario o anarquismo social. 
histórico llamamiento a la construcción de la Internacional de la Esperanza en contra de la «internacional del terror que representa el neoliberalismo», como dice la Segunda Declaración de la Realidad, y a la realización de la inmensa tarea de crear una red colectiva de todas nuestras luchas y resistencias específicas. Ese fue un llamamiento a la creación de una red intercontinental de resistencia contra el neoliberalismo [...]. Una red que, reconociendo las diferencias y las similitudes, iba a intentar unirse a otras resistencias de todo el mundo y ser el medio por el que las resistencias diferentes aprenden unas de otras (Löwy, 2004: 56-57).

\subsection{Los tres polos políticos}

El movimiento antiglobalización no es un bloque unitario. Este sistema de acción destaca por su diversidad, y con fines analíticos se puede dividir su composición en tres polos políticos. Teniendo en cuenta las diferentes ideologías, estrategias que activan y el tipo de organizaciones presentes en su seno se agruparían en los tres ejes siguientes: el político-institucional; el radical-político y el autónomo-libertario (González; Barranco, 2007: 270-272).

El polo político-institucional estaría conformado por las organizaciones políticas clásicas. Es decir, por partidos políticos presentes en las instituciones representativas y por los sindicatos mayoritarios. En Cataluña destacarían, entre los primeros, Iniciativa per Catalunya Verds (ICV) y Esquerra Republicana de Catalunya (ERC), y entre los segundos, Comisiones Obreras (CC. OO.) y la Unión General de Trabajadores (UGT). También se incluiría una parte de las grandes organizaciones no gubernamentales $(\mathrm{ONG})$ presentes en el territorio y las federaciones de asociaciones tradicionales. Este grupo se caracteriza por ser partidario de las reformas y por intentar «humanizar» el capitalismo. De este heterogéneo grupo habría que resaltar la acción colectiva desarrollada por las entidades que se caracterizan por ejercer su actividad dentro del sector de la cooperación internacional. Estas agrupaciones han pasado a ser denominadas por los teóricos sociales como novísimos movimientos o movimientos por la solidaridad. Nacieron a finales de los ochenta, y desde finales de los noventa están formando parte del movimiento antiglobalización. La mayor parte se presenta bajo la forma de ONG. 
El eje radical-político lo constituye la mayor parte de las entidades que desde 2003 han organizado los Foros Sociales y las contracumbres. En él se dan cita los miembros, colectivos y partidos de la izquierda radical, y una parte de los sindicatos alternativos. En Cataluña, dentro de este grupo destacan la acción de Revolta Global y En Lucha, una organización juvenil. También podemos integrar en este grupo a los partidarios de la izquierda independentista catalana. Entre sus organizaciones encontramos hasta 2001 la denominada Plataforma por la Unidad de Acción (PUA), que constituyó parte del movimiento independentista catalán y que en 1995 integró en su seno a los miembros de Catalunya Lliure y Maulets, así como a miembros de la Asamblea de la Unidad Popular, organización independentista impulsada en su día por el Movimiento por la Defensa de la Tierra-IPC. Desde 2001, será Endavant (organización socialista de liberación nacional) la que tome su relevo, acompañada por el Sindicato de Estudiantes de los Países Catalanes (SEPC) y la Candidatura de Unidad Popular (CUP), un partido con presencia en los municipios y en el parlamento regional catalán que se define en su página web oficial de esta forma:

La CUP es una organización política asamblearia de alcance nacional, que se extiende en los Países Catalanes y que trabaja por un país independiente, socialista, ecológicamente sostenible, territorialmente equilibrado y desligado de las formas de dominación patriarcales. La Candidatura de Unidad Popular (CUP) se articula como espacio útil para todas aquellas personas y colectivos con voluntad transformadora que luchan por la libertad de nuestro pueblo, con la intención de ser un espacio de confluencia de los movimientos cívicos y populares, en la lucha por la liberación nacional y social de los Países Catalanes ${ }^{4}$.

De esta organización política habría que destacar: su carácter asambleario y socialista; la voluntad de constituirse en un espacio que posibilite la confluencia a todos aquellos que luchan por la liberación del pueblo catalán; su apuesta decidida por formar parte de un frente antiglobalización; y la historia de resistencia de los colectivos que posibilitaron su nacimiento.

La CUP se situaría dentro de esta taxonomía en una posición ambigua. Esta deriva de ejercer la lucha por la liberación nacional de su pueblo en el seno de las instituciones democráticas (municipios y parlamento autonómico

4 Traducción propia de un texto extraído de su página web a través del enlace <http://cup.cat/qui-som $>$. 
catalán) y dotarse de formas de organización y órganos de decisión propios de la tradición anarco-comunista. Este carácter dual le permite ocupar un espacio intermedio entre el ala radical-política y los colectivos que conforman el tercer polo político del movimiento antiglobalización: el autónomo-libertario.

Este último se ha convertido en un cajón de sastre que contiene un amplio abanico de colectivos y entidades procedentes del ecologismo y la economía alternativa. Todo un foco de atracción para los desencantados de la democracia representativa y el sistema capitalista, partidarios de la acción directa y las okupaciones, una economía a «escala humana» o de anteponer el respeto a la naturaleza al crecimiento económico. En él destaca la actividad que desarrolla un núcleo duro conformado tanto por las clásicas organizaciones anarcosindicalistas como por colectivos autónomos. En el ámbito teórico habría que resaltar la influencia del discurso de los autores que dentro del movimiento antiglobalización apuestan por alcanzar la autonomía. Su acción colectiva se divide entre una actividad dirigida a la micromovilización en el ámbito local y un papel activo en los Foros Sociales. Pero sin duda lo más destacable de este círculo movimentista es el hecho de dar origen al Movimiento de Resistencia Global (MRG), un espacio de coordinación que constituyó el embrión del movimiento antiglobalización en España:

Se trata también de un polo muy amplio, y que a menudo atrae muchos colectivos temáticos del mundo de la solidaridad, el ecologismo y la economía alternativa. Su núcleo duro engloba desde el anarquismo tradicional (CNT) a las nuevas formas de organización libertaria y del ámbito de la autonomía (como el zapatismo y el movimiento okupa). Este polo se distingue por defender la estrategia de la generación de contrapoderes y huir de cualquier tipo de mediación política en la acción, celebrar la diversidad de identidades en el movimiento y centrarse en el trabajo en el ámbito de lo social, que se considera equivalente a lo político. Sus referentes teóricos, en el tema de la globalización, son también muy diversos y pueden incluir desde el italiano Toni Negri, a la canadiense Noemí Klein y el mexicano subcomandante Marcos, portavoz del EZLN. En general, de este polo ha sido desde donde se han utilizado más repertorios de acción directa basados en la desobediencia civil, como las okupaciones [...]. En Cataluña, de este polo surgió, en el verano de 2000, la iniciativa del primer espacio de coordinación del movimiento, el MRG, donde confluyeron con sectores del polo radical-político. Posteriormente, en la etapa 
de los foros, este polo se ha dividido en torno a dos orientaciones: la primera de ellas representaría a algunos sectores que perdieron el interés por el tema de las movilizaciones contra la globalización, centrándose de nuevo en el trabajo local, mientras que la segunda es la que organiza y constituye los espacios alternativos en los Foros Sociales (González; Barranco, 2007: 272).

De los tres círculos concéntricos del movimiento antiglobalización, este último es el central. Dio nacimiento en el año 2000 al Movimiento de Resistencia Global (MRG), una red de colectivos que creó el primer espacio de coordinación de esa amplia gama de grupos que constituye en la actualidad el movimiento antiglobalización. Hasta su autodisolución en 2003 se caracterizó por promover la movilización en el ámbito de la sociedad civil. Y en posicionar en el centro de la actividad económica y política a las personas para alcanzar una transformación integral del modelo actual de sociedad que genera el sistema capitalista.

Sus valores y principios anteponían: a la competitividad, la cooperación; a la desigualdad generada por el capital, la distribución equitativa; al interés individualista de una cultura que persigue el beneficio económico, el respeto a la dignidad de las personas y a la naturaleza; a la delegación política (democracia representativa), la participación de todos los individuos en las decisiones que les afecten (democracia directa); a la economía de mercado capitalista, una economía colectivizada, cooperativa y autogestionada; al trabajo asalariado, el valor de los cuidados no remunerados; a la fragmentación social, la unión bajo formas movimentistas para alcanzar la liberación del dominio (económico, político, etc.); a la apuesta «suicida» por el crecimiento económico, una economía local que fomente el decrecimiento; al poder de las instituciones internacionales que impulsan la globalización, el contrapoder de los movimientos sociales que nace de la solidaridad y respeta su autonomía.

En resumen, el MRG contrapone la cultura capitalista, que se extiende a nivel global y lleva a unas relaciones sociales «tóxicas», a «otro modo de vida» sustentado en una serie de valores, creencias y normas que lleve a acabar con la desigualdad y la injusticia. Estos principios de acción determinarán el ethos, el carácter o tendencia del movimiento, y quedan fijados en el manifiesto fundacional que realiza el MRG en septiembre del año 2000: 
Consideramos que la respuesta está en la movilización de la sociedad civil. Es una urgente necesidad encontrar alternativas al modelo económico imperante. Se debe situar los seres humanos como eje y centro de la vida social y de la actividad política, lo que significa que la satisfacción de las necesidades de las personas de todo el mundo y el ejercicio de sus derechos tienen que estar garantizados por encima de cualquier otra consideración, por encima de la rentabilidad de las inversiones o la competitividad de la economía. La cooperación y la solidaridad tienen que sobreponerse a los intereses particulares garantizando la equidad y el equilibrio en el reparto de la riqueza y el trabajo. En especial, es preciso hacer frente a la desigualdad creciente entre Centro y Periferia y plantear una cultura alternativa del trabajo a escala planetaria, basada en los planteamientos anteriores. Entendemos la libertad como la facultad que tenemos tod@s para pensar e intervenir en las actividades que nos afectan, por tanto, es necesario redescubrir el valor de la democracia en la política, más allá del elitismo y profesionalismo de los actuales partidos políticos. Es necesario descubrir el valor de la economía colectivizada y cooperativa a pequeña escala, más allá del capitalismo. En este sentido, es de gran importancia potenciar el diálogo y la convergencia en aquellos movimientos sociales que defienden el control, por el conjunto de la sociedad, de las actividades políticas y económicas. Debemos aprender a practicar y valorar las diferentes formas de trabajo humano, no solo el trabajo remunerado, como vías de realización personal, de construcción comunitaria y reconocimiento de los derechos. Otro valor central es la defensa del equilibrio ecológico y el respeto de la naturaleza. Es necesario un replanteamiento del actual modelo de crecimiento y consumo tanto en el ámbito personal como colectivo, así como revalorizar la importancia de la economía local. En definitiva, debemos plantearnos una nueva forma de entender las relaciones entre las personas, de carácter universal, acabando con el capitalismo depredador, y en el marco de una sociedad que pondría en primer plano la participación entre los seres humanos y la abolición de las desigualdades sociales ${ }^{5}$ (MRG, 2000).

La presencia de este tipo de organizaciones podría responder, por lo que se refiere al polo menos moderado del movimiento antiglobalización (el grupo radical-político y el autónomo-libertario), a la necesidad de dar una salida a la profunda crisis ideológica derivada de la caída del «socialismo real» y la desa-

5 Texto extraído del enlace: <http://www.nodo50.org/praga00/manifiesto.htm>. 
parición del imaginario utópico que sostuvo los proyectos de transformación durante el siglo $\mathrm{xx}$. En lo relativo al sector moderado, estaríamos, en parte, ante una reacción a las políticas neoliberales que minan la democracia y debilitan el nivel de protección social que los Estados alcanzaron en sus respectivos territorios.

\subsection{La CIC y el anarquismo extramuros}

Abordar un fenómeno tan complejo y multidimensional como el movimiento global de resistencia contra el neoliberalismo y sus expresiones locales exige cierta amplitud de miras. Si nos centramos en la Cooperativa Integral Catalana (CIC), podremos observar que el anarquismo clásico se ha diluido a lo largo del siglo Xxi en la extensa red de movimientos sociales (ecologista, hacker, queer, okupación, 15M, etc.) y ha pasado a conformar parte de sus valores, principios y prácticas, generando una manera de hacer, de organizarse, una cultura de resistencia inspirada en la tradición libertaria que dota a una parte de los sistemas de acción de unos rasgos comunes y constituye el denominado anarquismo extramuros ${ }^{6}$ :

Para evitar posibles malentendidos, conviene precisar que no se trata aquí de enrolar, bajo la bandera del anarquismo, unos movimientos que no se reclaman de él, y de calificar de anarquismo cualquier manifestación popular de base en la democracia directa. Ni la gran manifestación de Seattle, ni el movimiento 15M, ni Ocuppy Wall Street fueron anarquistas, y sus derivas posteriores pueden, incluso, acabar contradiciendo sus iniciales tonalidades libertarias. El anarquismo no consiste solo en ciertas modalidades organizativas formales, sino que se basa también en unos contenidos que son fundamentales para caracterizarlo. [...] Es innegable que los movimientos a los que me refiero aquí presentan un «aire de familia» con el anarquismo que los sitúa claramente en su campo ideológico, y que estas manifestaciones forman parte del anarquismo en acto, aunque no reivindiquen el nombre y aunque alteren un poco sus formas tradicionales. Es, en parte, para designar esta forma de anarquismo un tanto difuso, no identitario, forjado directamente en las luchas contemporáneas y exterior al movimiento anarquista, por lo que recurro a la expresión anarquismo extramuros (Ibáñez, 2014: 27).

6 Tomás Ibáñez (2014) emplea esta expresión en su libro Anarquismo es movimiento. Anarquismo, neoanarquismo y postanarquismo. 
En este tejido sincrético, híbrido y movimentista, la identidad se reformula constantemente para posibilitar la confluencia. La convergencia, la unión, generará la sinergia que potencia las luchas. Un entorno que puede concebirse como laboratorio social y como semillero de propuestas alternativas que pasan a concretarse gracias al paraguas legal del CIC. Un espacio que permite la extensión de una cultura de resistencia y la incorporación de activistas o simpatizantes para las diversas causas que allí se dan cita. Resumiendo, este marco común inspirado en la tradición libertaria y en permanente construcción posibilita la generación de un espacio que dota de recursos a un conjunto de actividades, resistencias y deseos que rechazan el orden neoliberal hegemónico y proponen líneas de fuga forjando itinerarios alternativos.

\subsection{Contraimperio}

La Cooperativa Integral Catalana (CIC) forma parte de un proyecto global de liberación, es una expresión local de un conjunto de movimientos que luchan por emanciparse y zafarse de lo que consideran un sistema de dominio multidimensional que opera abarcando todo el campo social. Escapar de la sociedad del control, del poder que se extiende penetrando en las conciencias, es su meta.

La multitud $^{7}$ que en la modernidad protagonizó la lucha de clases se enfrenta ahora a un régimen de biopoder en el que la producción económica y la constitución política se funden. El enemigo no es la globalización, sino un régimen concreto de relaciones que abarca la totalidad del planeta: el imperio.

Podemos concebir las luchas que emergen (EZLN, MST, etc.) contra esta nueva forma de dominio no como el advenimiento de un nuevo ciclo de resistencia internacionalista, sino como la aparición de una nueva calidad de movimientos sociales (Hardt y Negri, 2002: 66). Estos poseerían nuevas propiedades que permitirían distinguirlas de las anteriores. Su primera característica

\footnotetext{
7 Hardt y Negri (2004) utilizan el término multitud en sus obras como concepto de clase. Entienden por multitud un conjunto de singularidades que actúan unidas. La multitud se gobierna a sí misma y representa el único sujeto social capaz de realizar la democracia, entendida esta como el gobierno de todos por todos. Desde el punto de vista socioeconómico representaría al sujeto productivo de la etapa posmoderna. Estos pensadores creen que la multitud, en un futuro, debe liberarse del dominio del capital, desarrollar una producción basada en el común, emerger desde la autonomía y gobernarse a sí misma. La potencia del concepto estriba en que no existe contradicción entre singularidad y comunalidad. No implica, por tanto, elegir entre unidad y pluralidad, ya que ambas son compatibles. Se funda esencialmente en sus condiciones de posibilidad y no en la existencia empírica actual. En su concepción restringida se concibe como la totalidad de los que trabajan bajo el capital y forman, en potencia, la clase que no acepta el dictado del capital.
} 
distintiva sería la capacidad para saltar de la esfera local a lo global de forma inmediata. Aunque mantienen un firme compromiso y arraigo a nivel local, transitan al global para hacer frente al dominio del imperio. La segunda se centra en acabar con la distinción existente entre luchas económicas y políticas. Estos movimientos han puesto fin a la distinción que tradicionalmente se concebía entre la batalla política, la económica y la cultural. Nos hallamos ante una lucha biopolitica:

La acción revolucionaria no puede realizarse o siquiera pensarse con éxito en un solo ámbito. [...] La revolución solo puede avanzar como un ciempiés o, a decir verdad, como una multitud. Solo en el campo de las luchas biopolíticas, compuestas mediante paralelismo y multiplicidad, puede llevarse a cabo con éxito una lucha revolucionaria por el común (Hardt y Negri, 2011: 344).

La CIC representaría un ejemplo paradigmático que expresa en España estos cambios en el seno de los movimientos sociales. En ella se observa a una lucha local que transita de forma inmediata a la global y batalla en el campo biopolítico para crear nuevos espacios y comunidades en su intento de construir un camino hacia la liberación. El proceso iniciado por la CIC se fija como objetivo superar la modernidad para alcanzar por fin el sueño de una revolución puesta al día. Una transformación que llevará a nuevas estructuras, nuevos valores e instituciones, en una nueva etapa que Hardt y Negri definen como altermodernidad:

Las luchas revolucionarias paralelas deben descubrir cómo intersectarse en acontecimientos insurreccionales y preservar sus procesos revolucionarios en formas institucionales. [... ] la tríada identidad-propiedad-soberanía que define la modernidad es reemplazada en la altermodernidad por la singularidadcomún-revolución. La revolución se ha puesto, finalmente, al orden del día (Hardt y Negri, 2011:345).

El discurso que emana de las publicaciones de la CIC denuncia que no existe en esta etapa histórica de acumulación y mercantilización capitalista el proclamado libre juego y la igualdad, sino la imposición de jerarquías. Para hacer frente al sistema económico capitalista y al Estado, la CIC apuesta por la desobediencia civil. Rehusar someterse a la autoridad posibilita el comienzo de una política liberadora. Pero van más allá de la simple denegación y, apoyándose en esta, construyen un nuevo modo de vida, una nueva comunidad. 
En la Cooperativa Integral Catalana, como sugieren Hardt y Negri (2002: 196), el proyecto concreto de liberación surge de la práctica revolucionaria. El contraimperio se ha de extender globalmente, desde abajo, brotando del esfuerzo diario de las personas, colectivos y movimientos que se comprometan en la lucha. Esta tarea se concibe como una fase de experimentación, un paso adelante que llevará posteriormente a una reflexión teórica. Del mismo modo que Marx utilizó la Comuna de París para elaborar el comunismo, la multitud ha de poner en marcha nuevas formas sociales, ensayar sobre el terreno, probar su viabilidad. Desde la óptica activista, esta fase posibilitaría edificar un cuerpo social autónomo libre del poder del imperio.

La CIC apuesta por ubicar el poder de la multitud no en las instituciones representativas, sino en un proceso que lleve a la autonomía. Para llegar a ella es necesaria una nueva producción de la subjetividad. Más allá de la lucha por los beneficios sociales empleada por los partidarios de la reforma, se pretende generar un cambio radical centrado en el estilo de vida.

En el imaginario de la CIC producir es construir cooperación, edificar comunidades cooperativas donde el concepto de propiedad privada no tiene sentido y lo común prevalece. La política no es una esfera independiente y el consenso ya no se determina mediante los mecanismos tradicionales de mediación política. Las organizaciones de trabajadores que durante los siglos XIX y $\mathrm{xx}$ han ejercido la resistencia al dominio capitalista han perdido poder y se muestran ineficaces para favorecer la revolución dentro del régimen político nacional. En esta situación no es viable transformar la sociedad utilizando los instrumentos del Estado. Hay que construir una nueva forma de resistencia; Hardt y Negri la denominarán contraimperio.

\subsection{Hacia la Revolución Integral}

La multitud no surge como figura política de forma espontánea, tampoco su existencia asegura que su proyecto de liberación del capital aboque a un nuevo régimen de explotación y control. Para conseguir alcanzar la meta de la autonomía a través de la autogestión se necesita un marco de referencia que oriente y guíe un proceso político. En la CIC este marco se denomina Revolución Integral.

La Cooperativa Integral Catalana (CIC) es, además de un paraguas legal para evitar la represión de la Administración pública por la práctica de la des- 
obediencia civil (okupación, insumisión fiscal, etc.), un lugar de encuentro, un espacio común de socialización conformado por una red de pequeños proyectos y comunidades, constituido por un núcleo de activistas procedentes de diversos ámbitos de la izquierda anticapitalista. A todos ellos les une la lucha por lo que han venido a denominar Revolución Integral, un proyecto que persigue una sociedad basada en la autonomía. La noción de Revolución Integral dota al grupo de una guía básica que proporciona las bases de su ideario, lo orienta y posibilita a otros movimientos o colectivos afines que puedan sentirse cómodos en este marco y confluir en la CIC.

El colectivo ${ }^{8}$ que realiza el llamamiento ${ }^{9}$ para la creación del Bloque para la Revolución Integral es promotor de un espacio ideológico que intenta sentar las bases de la revolución. Esta se expresa de forma esquemática pero concisa como un proceso que trata de acabar con las formas en que el poder se extiende a lo largo del cuerpo social. Pero no se queda ahí, va más allá, el éxodo que inicia exige una «tierra prometida» que está por alcanzar. Estamos ante una línea de fuga que señala una fase de transición donde se construye una alternativa real al sistema actual. El éxodo ha de ser constituyente, el esfuerzo colectivo va dirigido no únicamente a la destrucción, sino a la construcción de un nuevo modo de vida, una estructura social y unas instituciones que posibiliten a los que hayan tomado el camino de llegar a un mundo más humano, más justo:

Revolución: transformación radical de las estructuras y valores que fundamentan una sociedad. Integral: que contiene todos los elementos que puede tener para ser completo. Revolución Integral: proceso de significación histórica para la construcción de una nueva sociedad autogestionaria, basada en la autonomía y la abolición de las formas de dominación vigentes: el Estado, el capitalismo y todas aquellas que afectan a las relaciones humanas y a la relación con la naturaleza. Implica una acción consciente, personal y colectiva, para la mejora y la recuperación de las cualidades y los valores que nos capaciten para una vida en común. Al mismo tiempo, implica la construcción de nuevas formas y estructuras organizativas en todos los ámbitos de la vida que garanticen igualdad de decisión y equidad en la cobertura de necesidades vitales ${ }^{10}$.

\footnotetext{
8 Se puede ampliar información sobre este grupo en su página web: <http://integrarevolucio.net/es/ > . 9 Podemos acceder al documento a través del enlace: <http://integrarevolucio.net/es/documents/>. 10 Texto publicado en la web: <http://integrarevolucio.net/es/revolucion-integral/que-entendemos-porrevolucion-integral/>.
} 
La Revolución Integral, objetivo de este núcleo de activistas, nace con vocación de extenderse no solo a lo largo y ancho del territorio nacional, sino más allá de sus fronteras. Es la iniciativa de vincular la lucha por la autonomía bajo prácticas que se inspiran en la tradición libertaria (proceso asambleario, búsqueda del consenso, colectivización, etc.) y que expresan el intento de prefigurar un proyecto de transformación económica, política, social y cultural de la sociedad. Con este fin dan forma a una organización de estructura reticular, orientada por un conjunto de valores que permiten constituir un marco de referencia amplio y dinámico. Los activistas procedentes de diversos movimientos (decrecimiento, anarquismo, 15M, economía solidaria, okupación, ecologismo, hacker, queer, etc.) encuentran en las Bases ideológicas de la Revolución Integral ${ }^{11}$ un punto de partida y un objetivo común.

El colectivo que intenta impulsar el Bloque expresa una propuesta global: en su contenido, pues ha de comprender todos los ámbitos de la vida de las personas (salud, educación, alimentación, trabajo, etc.), y en su extensión, ya que esta iniciativa ha de vincularse a otras luchas con las que guarda afinidad y se dan en el resto del mundo. En este camino de transición nace la necesidad de resistir generando una estructura reticular que desea extenderse sin centro aparente, de formar frentes comunes bajo dinámicos y flexibles marcos ideológicos que se construyen transnacionalmente. En el proceso se reformulan corrientes de pensamiento (anarquismo, autonomía, ecologismo, etc.) que van construyendo el imaginario colectivo del grupo, gestando una cultura híbrida, una identidad en continua construcción que se mantiene gracias a la disposición permanente de resistir el dominio del Estado y la hegemonía del mercado. Para los partidarios de la revolución integral estos dos últimos componentes estructurales minan la dignidad del ser humano y provocan la respuesta de los pueblos que sufren la explotación, la amenaza del fin de su cultura y la humillación de su población.

La Revolución Integral de la CIC genera un espacio internacional de confluencia, un grupo de activistas que posibilita el trabajo en red entre movimientos de liberación; en la práctica: implica mantener relaciones de solidaridad y de apoyo mutuo. Frente a la democracia parlamentaria, el neoliberalismo económico y el Estado, presentan la creación de una nueva sociedad que desde la

11 Podemos acceder al documento a través del enlace: <http://integrarevolucio.net/es/revolucion-integral/ bases-ideologicas-del-1lamamiento/>. 
autogestión edifique los cimientos de la autonomía. Se han de plantar las semillas (comunidades y proyectos) que posibiliten vivir bajo otros valores, principios, normas y estructuras.

\section{El éxodo}

Para los activistas de la $\mathrm{CIC}$, los medios que producen la realidad social en la actualidad se han modificado e instaurado un nuevo modelo de dominio. Hardt y Negri nos muestran a través de su trilogía los elementos clave para la comprensión de este proceso. Describen el tránsito de la sociedad disciplinaria a la sociedad del control. En la primera, una red de instituciones disciplinarias (la fábrica, la escuela, los psiquiátricos, la prisión, etc.) establecen los límites del pensamiento, prescribiendo y sancionando las conductas consideradas desviadas. Este primer paradigma de dominación estaría presente en su forma más pura a lo largo de la primera fase de acumulación capitalista.

Este modelo inicial habría sido sustituido progresivamente por nuevos mecanismos de dominio, que lo distribuirían a lo largo de todo el campo social impactando sin límites fuera de las instituciones en las mentes y cuerpos de la población. Los ciudadanos interiorizarían las conductas adecuadas para que el poder y sus élites siguieran ejerciendo su dominio. Las instituciones sociales seguirían moldeando las conciencias, pero el control se habría extendido fuera de ellas tomando forma de red cuyas propiedades permitirían la flexibilidad y el flujo constante, un proceso que genera biopoder: «la tendencia de la soberanía a convertirse en poder sobre la vida misma» (Hardt; Negri, 2004: 379).

El poder ejercería su dominio efectivo administrando la vida social de forma integral. Los ciudadanos interiorizarían las normas y responderían apoyando el sistema. La sociedad del control sería el resultado de la eficacia de este nuevo paradigma que cubriría las carencias del anterior modelo de dominio traspasando e impregnando ahora sin obstáculos la totalidad de las relaciones sociales.

Para Hardt y Negri, el poder se torna biopolítico al convertir la vida social en su objeto. La fuente del poder nace de la máquina de producción social y no del derecho. El imperio no se presenta como un orden jurídico, su legitimidad brota de la producción biopolítica globalizada. En esta situación, la resistencia 
ha de emerger desplegándose en forma de red en el seno de la sociedad del control y atacar la legitimidad en la misma base de su producción.

Lo económico, lo social y lo cultural se unen formando el ámbito de lo biopolítico, un espacio de producción que puede transformarse en una excelente plataforma para la resistencia. Pues bien, la CIC apuesta por el desarrollo del tejido biopolítico para construir espacios de liberación que posibiliten a sus miembros escapar de la sociedad del control. Esta entidad pone a disposición de sus miembros un conjunto de herramientas que permiten transitar hacia un nuevo mundo. Su objetivo: dejar atrás el dominio que se ejerce a través del biopoder. Este se instala en el interior de la vida social para regularla. Escapar de su control requiere retirarse de la relación que mantiene con él, y esa «huida» es un potente instrumento para la resistencia y constituye el éxodo de la CIC:

Por éxodo entendemos aquí, al menos inicialmente, un proceso de sustracción respecto a la relación de capital mediante la actualización de la autonomía potencial de la fuerza de trabajo. De esta suerte, el éxodo no es un rechazo de la productividad de la fuerza de trabajo biopolítica, sino más bien un rechazo de las argollas cada vez más restrictivas colocadas sobre la capacidad productiva por el capital. [...] Cabe pensar esta primera forma de lucha de clases como una especie de cimarronaje. Como los esclavos que escapan colectivamente de las cadenas de la esclavitud para construir comunidades y quilombos autogobernados, el trabajo biopolítico, sustrayéndose de su relación con el capital, debe descubrir y construir nuevas relaciones sociales, nuevas formas de vida que le permitan actualizar sus potencias productivas. Pero, a diferencia de los cimarrones, este éxodo no significa irse a alguna parte. Podemos emprender una línea de fuga quedándonos en el mismo sitio, transformando la relación de producción y el modo de organización social bajo el cual vivimos (Hardt y Negri, 2011: 165).

\section{1 ¿Cómo logran la liberación?}

Los activistas de la CIC entienden que el sistema capitalista ha creado una sociedad que participa del mantenimiento de sus propias cadenas, de su dominio, convirtiéndose ella misma en el guardián del orden no solo a través de sus estructuras institucionales, sino de la estructuración de la conciencia individual. 
Desde la óptica activista, no hay otra salida que escapar de sus redes e intentar generar un nuevo nomos. Este nuevo orden significativo no se producirá espontáneamente, sino que será el resultado de la interacción social que se produzca en los encuentros entre singularidades, entre personas y colectivos, movimientos y fuerzas de liberación que desde la diversidad se integren en un orden de significado común.

La creación de un nuevo mundo social liberador que regule todos los elementos tenderá a ser totalizador (Berger, 1969), «imponiendo» un orden común de interpretación que se concibe dinámico, en construcción. Frente a la anomia, la falta de sentido, la incapacidad del actual sistema socioeconómico para dotarnos de una estructura social que produzca los recursos que posibiliten y potencien la vida, no hay otro camino que recuperar los mecanismos que dotan de sentido a la experiencia.

La CIC se marca como prioritaria la concienciación de una masa crítica en unos valores que lleven a su ruptura con la sociedad actual. Concebida esta como enferma, como una muestra salvaje del deterioro ético que ha sufrido la población en la modernidad, promueven la construcción de una sociedad paralela que han de impulsar a través de su acción colectiva y en donde el recurso de la concienciación se convierte en un instrumento que busca alcanzar la liberación cognitiva ${ }^{12}$, un proceso que se beneficiaría en gran medida por el clima sociopolítico generado en un contexto de profunda crisis económica.

Hasta la fecha, nunca se habían dado las condiciones necesarias para que un proceso de concienciación que propugnara el fin de la sociedad capitalista pudiera tener ciertas garantías de éxito. El Grupo de Reflexión para la Autonomía $^{13}$ (GRA), constituido por activistas que dan origen y desarrollan la noción de Revolución Integral en la CIC, pone de relieve que es el momento adecuado

12 Bert Klandermans habla de este proceso en su artículo «La construcción social de la protesta y los campos pluriorganizativos» (2001): «McAdam (1982 y 1989) propuso el concepto de liberación cognitiva para referirse a la transformación de la conciencia de los participantes potenciales en la acción colectiva. Hace referencia a Pive y Cloward (1979) al describir la liberación como un cambio de conciencia en tres sentidos: a) el sistema pierde legitimidad; b) la gente que normalmente es fatalista empieza a exigir cambios; $y c$ ) hay un nuevo sentido de eficacia. Según McAdam, las transformaciones de las condiciones políticas son un impulso fundamental para el proceso de liberación cognitiva al provocar un cambio en el contenido simbólico de las relaciones sociales de defensores y críticos del sistema político. El hecho de que los primeros cambien de actitud hacia los segundos indica a todos los que están en contra del sistema que este se está haciendo cada vez más vulnerable a sus ataques» (pág. 186).

13 Podemos ampliar la información sobre este colectivo y acceder a sus publicaciones accediendo a su página web: <ttp://www.grupreflexioautonomia.org/es/>. 
para su proyecto revolucionario, el contexto «invita» a iniciar el éxodo, el sistema pierde credibilidad y sus valores se ponen en cuestión:

Hoy este mundo está en crisis. En Occidente se desploman los valores de una civilización: la organización político-económica comienza a hacer crisis, la abundancia de recursos materiales y la ficción del crédito han tocado techo, el ejército de reserva no para de crecer y se entrevé la verdadera naturaleza del trabajo asalariado como forma de esclavitud, falsa libertad en un mundo con cadenas. El hecho de que el sistema cada vez pueda satisfacer menos las propias expectativas y promesas le hace perder credibilidad y fuerza. Así, se nos abre una ventana de oportunidad, un momento en que se hacen muy evidentes las contradicciones del propio sistema y la incapacidad del Estado y el mercado para cubrir las necesidades humanas básicas. Esta ventana se abre tras décadas de desarrollo del Estado de bienestar en Occidente, de aniquilar las comunidades y sus lazos de ayuda mutua dejando solo individuos aislados e insociables ${ }^{14}$.

Pues bien, dentro de este contexto altamente favorable tanto para el desarrollo de proyectos orientados a la reforma como para propuestas alternativas o de perfil revolucionario, habría que distinguir a la CIC del resto de movimientos más «convencionales» por el grado de impacto que desea alcanzar mediante el proceso de liberación cognitiva. La concienciación va más allá de la consecución de la activación de una protesta por parte del movimiento, de la generación de una masa concienciada en la legitimidad de lucha y en su posible éxito.

El proceso de liberación cognitiva ha de ser profundo y socavar los cimientos culturales en los que se asienta la civilización occidental; las estructuras e instituciones actuales son concebidas como corruptas e ineficaces. Para que esta revolución se lleve a efecto es necesario diseñar una nueva forma de vida, una nueva cultura. Las creencias, las costumbres, los valores y la conducta han de ser modificados. Han de generar un puente que una el pasado, marcado por la vida comunitaria y los valores espirituales, con un futuro donde su acción colectiva conquiste la hegemonía cultural, y el sistema capitalista sea tan solo un mal recuerdo, una etapa salvaje que olvidar:

14 Fragmento del artículo «¿Reforma o revolución? Pensando la transformación social hoy». Publicado por el GRA en su página web el 16/04/2015 y en la web de la CIC (<http://cooperativa.cat/es/>) el $15 / 05 / 2015$. 
Actualmente nos encontramos en un mundo hiperindustrializado, depredador de recursos, regido por una economía de mercado salvaje y grandes Estados, instituciones que se disfrazan de garantes de la seguridad y la libertad, pero que en realidad no son más que máscaras para mantener los regímenes de dominación y de explotación. En estos territorios sobreviven individuos individualizados e individualistas, alienados y cómplices del sistema, que en su mayoría no se cuestionan el orden establecido, sino que optan por una apatía y un victimismo conformista. [...] Para poder establecer una sociedad autónoma se requieren personas mínimamente autónomas y, por tanto, tenemos que construir la autonomía tanto a nivel de los individuos como de las instituciones, tenemos que arrancar las malas hierbas de raíz, extrayéndolas también de nuestro interior, forjado en el proceso de socialización de una sociedad enferma. Así, si bien muchas veces se ha asociado la revolución con periodos breves de tiempo, pensamos que para que una verdadera revolución sea posible nos hace falta al menos el tiempo y esfuerzo suficientes para consolidar una firme conciencia revolucionaria ${ }^{15}$.

Los miembros de la CIC son conscientes de la dificultad de implantar principios, valores y prácticas antagonistas con el sistema capitalista y el dominio estatal en la sociedad actual, con un sistema económico y político hegemónico que lleva a la población, ávida de consumo y temerosa de perder el cada vez más reducido estado de bienestar, a no participar en proyectos que exigen librarse del dominio del mercado y del «manto protector» del Estado. Por lo que optan, en lo que podría constituir una segunda fase $e^{16}$ de un proyecto revolucionario concebido como global, es por intentar facilitar a sus miembros la creación de una red de iniciativas volcadas en la construcción y promoción de nuevas subjetividades. Semillas que, liberadas del influjo pernicioso que la sociedad capitalista ejerce sobre la población, pueden dar lugar a nuevas instituciones y a la transformación interior de sus miembros:

15 Texto extraído del artículo: «¿Reforma o revolución? Pensando la transformación social hoy», publicado por el Grupo de Reflexión por la Autonomía (GRA) en la página web de la CIC el 15/05/2015.

16 La primera, iniciada por el EZLN, llevó a la creación del movimiento antiglobalización y a los actos de protesta dirigidos a captar la atención mediática (Seattle, Praga, etc.). En la actual (la segunda), la CIC se concentra en mantener la llama en los espacios de resistencia que se han ido generando tras el ciclo de protestas; en intentar crear red en los tres ámbitos (local, nacional e internacional) para fortalecerse y potenciar su organización; y en la producción de la subjetividad mediante la socialización en otros valores de sus miembros. 
El núcleo principal de la producción biopolítica [...] no es la producción de objetos para sujetos, sino la producción misma de la subjetividad. Este es el terreno del que debe de partir nuestro proyecto ético y político. [...] uno de los escenarios decisivos de la acción política hoy implica la lucha en torno al control o la autonomía de la producción de la subjetividad. La multitud se hace a sí misma componiendo en el común las subjetividades singulares que resultan de este proceso (Hardt y Negri, 2011: 12).

Esta autotransformación se potencia en el seno de los grupos. La CIC construye colectivamente un marco de referencia que puede ser interiorizado a través de la práctica de la desobediencia, de la praxis revolucionaria. El proceso de concienciación es flexible y libre, ya que parte del propio individuo, pero apoyado en un entorno facilitador con calor comunitario que ha de posibilitar un conjunto de experiencias que lleven a entender la realidad y dotarla de sentido dentro de los postulados básicos que el movimiento se ha marcado.

\section{2 ¿Qué deben abandonar?}

La Cooperativa Integral Catalana (CIC) continúa y transforma el imaginario en el que se apoyó la acción obrera de los siglos xix y xx. En esa etapa el conflicto entre proletariado y capital se situaba preferentemente en el seno de las fábricas. En la actualidad, una vez desaparecido el sujeto histórico, protagonista en su día del cambio revolucionario, adapta su lucha al contexto de producción biopolítica: «La producción ya no se limita a la fábrica o a otra sede separada, sino que se extiende por todo el territorio social» (Hardt y Negri, 2011:250). Los activistas de la CIC dirigen su acción no directamente contra el capital propietario de los medios de producción, sino contra la sociedad capitalista en su conjunto. Para luchar contra la explotación y la alienación, construyen un proceso de éxodo de la sociedad del capital que les ha de llevar a «otro mundo posible» donde creen que podrán liberarse del yugo capitalista.

La CIC posibilita ese éxodo a quien desee escapar del control estatal y del mercado capitalista. Desde la óptica activista, su entidad nos abre las puertas a un camino de transición. Entienden que este se iniciaría en una sociedad donde el dominio del capital haría del poder soberano (entiéndase estatal) un mero siervo, un lacayo de la oligarquía global, el fiel criado de una nueva aristocracia que ahora basa sus privilegios en el poder económico y que impone su dominio 
a través de la lógica del dinero, convirtiendo la economía en un casino; y esta transición conduciría a un nuevo mundo, donde las relaciones (sociales, económicas y políticas) se conciben armónicas, gracias al desarrollo de las capacidades de autoorganización que sus miembros hayan ido desarrollando durante el proceso de liberación.

Escapar de la tupida red que nos envuelve de las más diversas formas, pero que determina o condiciona nuestra vida, para emprender la senda que nos ha de llevar hacia «un mundo donde quepan muchos mundos» ${ }^{17}$. Un lugar donde la economía esté supeditada al control político de una multitud, y las singularidades que la constituyen posibiliten la igualdad y el fin de los privilegios. Ese sería el horizonte que los activistas de la CIC vislumbran por los recodos de un camino en y de construcción. Una travesía marcada por la esperanza, una utopía que se aleja de un mero juego resultado de la imaginación, para marcar e impulsar el éxodo. Una vía de escape de lo que conciben como barbarie actual, un «progreso» sin rumbo, una jungla especulativa y destructora de toda forma de vida (social, cultural o natural).

\section{3 ¿Hacia dónde se dirigen?}

La Revolución Integral que se impulsa desde la CIC es el llamamiento hacia la salvación de la esencia humana. En el marco de diagnóstico que construye la Cooperativa Integral Catalana, la civilización occidental se derrumba y anda como un zombi carente de espíritu, que devora cultura y valores, destruyendo a su paso nuestro entorno natural. Pero no todo está perdido: si nos liberamos del dominio capitalista y estatal, recuperaremos nuestra libertad y, con ella, la posibilidad de construir un nuevo ser. Esta situación exige una actitud que visibilice el papel primordial que ejerce la resistencia, una lucha que en la CIC toma forma de éxodo. Este no exige un tránsito espacial, sino axiológico, emocional, existencial, hay que generar una nueva sociedad en la cáscara de la vieja y corrupta civilización occidental. La transición hacia una nueva etapa ha de recuperar el deseo por un mundo mejor, el impulso que potencie la generación de una nueva humanidad:

Nada funciona bien, ninguno es como debiera. Nadie está dispuesto a batirse por ideales. En nadie se puede confiar y nadie asume responsabilidades. La

17 Lema del movimiento liderado por el Ejército Zapatista de Liberación Nacional (EZLN). 
abulia, cobardía e irreflexión campean por doquier. Vivimos como seres sin espíritu, mera suma de apetitos fisiológicos y flojedad anímica. El dinero y el ansia de goces son las únicas motivaciones. La libertad no cuenta, y el Estado, junto con la gran empresa capitalista, lo domina todo. Estamos ante una gran crisis de la civilización y una inmensa declinación de lo humano, además de un colosal desplome de la libertad. Esta situación no es nueva, ni mucho menos. Hace mucho que Occidente ha perdido su cultura, que carece de valores, que es meramente una inmensa masa descompuesta que solo desea pan y circo a costa del medio natural y del Tercer Mundo. Vivimos desde hace mucho tiempo sin ideas, sin convicciones, sin alma, como seres puramente fisiológicos. $Y$ de eso tenemos que sentirnos culpables y responsables, pues a estas alturas ya no valen victimismos. Salvar la esencia humana concreta, que se pierde al parecer sin remedio, es la gran cuestión de nuestro tiempo. Eso exige una revolución integral ${ }^{18}$.

En esta situación, la movilización para la reforma no se plantea, la solución es la creación de «otro mundo», una nueva sociedad: que se organice mediante asambleas populares; recupere la propiedad como bien común con posesión y control popular; que acabe con el Estado y el mercado capitalista; impulsora de una economía basada en la cooperación y las relaciones de proximidad, que facilite una nueva relación con la naturaleza y haga posible el encuentro entre la tradición y la revolución:

La intolerable Constitución de 1812, que inicia coercitivamente el periodo liberal y parlamentarista e institucionaliza el capitalismo, negó personalidad jurídica al concejo abierto, forma sutil de buscar su destrucción. Al mismo tiempo fue aniquilando sus fundamentos económicos, el comunal, así como su base ideológica, el espíritu de comunalidad, ayuda mutua, repudio al dinero, rechazo del placerismo, consumo mínimo, preferencia por lo espiritual, esfuerzo desinteresado, virtud personal y negación del egoísmo. Lo propio de la tradición de los pueblos peninsulares es la asamblea, siendo el parlamentarismo, igual que el fascismo (en sus tres variantes, militar, civil y religiosa), una imposición extraña y ajena. Así se unifica tradición y revolución, pasado y futuro ${ }^{19}$.

18 Texto extraído de la publicación ¡Rebelaos! (pág. 12), producida por la CIC a través del colectivo Afinidad Rebelde. Se puede descargar en formato PDF en la web: <http://enricduran.cat/>.

19 Texto extraído de la publicación ${ }_{i}$ Rebelaos! (pág. 17). 
Los miembros de la CIC abogan por recuperar los valores de la vida en las pequeñas comunidades que marcaron la vida diaria de la población en la sociedad preindustrial. El proceso abierto por el periodo liberal y el parlamentarismo en el inicio de la modernidad destruyó el modo de vida de la sociedad campesina imposibilitando el desarrollo de las economías de supervivencia basadas en el común ${ }^{20}$. Estas permitían la autonomía a la población y generaban el contexto ideal para una base axiológica que potenciaba el fomento de la virtud y el rechazo al interés individual por encima del colectivo. El proceso de privatización ha acabado con los regímenes comunales. Ante esta situación hay que recuperar lo que anteriormente estaba abierto a todos y se desarrollaba con la participación activa de la comunidad. Para alcanzar una democracia real la comunidad ha de mantener, producir y distribuir el común:

Una democracia de la multitud imaginable y posible solo porque todos compartimos y participamos en el común. Por el común entendemos, en primer lugar, la riqueza común del mundo material (el aire, el agua, los frutos de la tierra y toda la munificiencia de la naturaleza) que en los textos políticos clásicos europeos suele ser reivindicada como herencia de la humanidad en su conjunto que ha de ser compartida. Pensamos que el común son también y con mayor motivo los resultados de la producción social que son necesarios para la interacción social y la producción ulterior, tales como saberes, lenguajes, códigos, información, afectos, etc. Esta idea del común no coloca a la humanidad como algo separado de la naturaleza, como su explotador o custodio, sino que se centra en las prácticas de interacción, cuidado y cohabitación en un mundo común que promueven formas beneficiosas del común y limitan las perjudiciales (Hardt y Negri, 2011:10).

Liberarse del peso del presente, donde el neoliberalismo y la democracia representativa constituyen en los planos económico y político las estructuras de dominación, lleva a construir lo que Fernando Aínsa (1999: 37) describe como contraimagen que se opone al presente. El pasado se idealiza y se reconstruye

20 Para Hardt y Negri (2004), el concepto de lo común va más allá de lo que entendemos como público o privado. Existe una tendencia en lo social a que todo sea público y, por lo tanto, a estar sometido al control de las autoridades, y en lo económico, a que todo sea privado y sujeto a derechos de propiedad. Ante esta situación proponen un marco de referencia alternativo que permita una privacidad que exprese la singularidad de las subjetividades sociales y no se entienda como propiedad privada, y un concepto de lo público basado en lo común y que escape al control estatal. Es decir, el desarrollo de un marco que posibilite a las comunidades controlar, en virtud de su propia actividad biopolítica, los recursos y bienes tanto materiales como inmateriales que posibilitan la reproducción de su comunidad. 
conformando una especie de nueva Edad de Oro, un paraíso en la tierra. Sin embargo, esta mirada nostálgica al pasado no implica regresar a él, sino extraer lo que de positivo tuviera para ser empleado en un futuro próximo en construcción. No lo disfrutamos en el presente, pero lo prefiguramos en nuestra acción, proporcionando las bases para su desarrollo, las semillas que permitirán el cambio revolucionario a través de nuevas estructuras que acaben con las injusticias. Tal y como indica Ernst Bloch: «El reino de la libertad no es un retorno, sino más bien un éxodo hacia una tierra prometida que se construye en el proceso mismo del tránsito» (Retamal, 2007: 473).

\section{Conclusión}

La Cooperativa Integral Catalana (CIC) se presenta como una estructura reticular de carácter complejo que tiende a formar una red distribuida o a presentarse como tal. Esta estructura se corresponde con la tendencia actual que sigue la producción económica y social. Es decir, adapta su estructura organizativa al modelo de producción hegemónico. Este modelo de red en forma de enjambre de abejas presenta una mayor resistencia a la represión que desde la CIC se espera que ejerza el poder estatal. Si bien la metáfora del enjambre puede sugerir igualdad entre sus miembros y falta de creatividad, en este tipo de estructura no se da:

Cuando una red distribuida ataca, acosa al enemigo con un sinnúmero de fuerzas autónomas que golpean un punto determinado, en todas direcciones al mismo tiempo, antes de desaparecer enseguida y regresar a su medio. Desde una perspectiva externa, el ataque en red se describe como un enjambre porque parece que no tenga forma. [...] Pero si se contempla el interior de una red, se observa que hay organización, racionalidad y creatividad. El modelo de enjambre sugerido por las sociedades animales $[. .$.$] plantea que cada agente o$ partícula del enjambre es idéntica a las demás y no posee creatividad propia. En cambio, los enjambres emergentes que vemos en las nuevas organizaciones políticas en red están compuestos por una multitud de agentes con distintos niveles de creatividad, lo cual añade varios grados de complejidad al modelo. Para comunicarse y cooperar, los miembros de la multitud no necesitan la uniformidad, ni renunciar a la creatividad individual (Hardt y Negri, 2004:121). 
Esta estrategia y la previsión, por parte de la entidad, del empleo de la represión por parte del Estado surgen de una resistencia que desafía el dominio del capital y el Estado para construir un contrapoder. La red de cooperativas integrales que impulsa la CIC desea extender la revolución a través de la construcción de un sistema que rompe los lazos de unión de sus miembros con el Estado y el mercado capitalista. El conjunto de herramientas que pone a disposición de sus socios a través de su proyecto está dirigido a potenciar el conjunto de cooperativas, pequeños proyectos, comunidades e iniciativas, que han de posibilitar la extensión de una red de resistencia:

Este tipo de cooperativas son un modelo para subvertir la salvaje realidad que padecemos como sociedad y como parte implicada del sistema de dominación capitalista, gestionado por unos pocos y apoyado y mantenido por el aparato estatal, que es quien le da de comer. Es por tanto una herramienta para construir contrapoder desde la base, partiendo de la autogestión, la autoorganización y la democracia directa ${ }^{21}$.

Los activistas de la CIC entienden que para alcanzar la revolución hay que construir una red que posibilite la emergencia de una nueva cultura, nuevas costumbres y prácticas colectivas que den lugar a una forma de vida acorde con sus principios. El éxodo debe llevar a consolidar un proceso institucional, crear un entorno que favorezca eliminar la corrupción que el capitalismo, entienden, ha provocado en las instituciones. Para ello se han de construir nuevos espacios que posibiliten generar una nueva cosmovisión, nuevos valores y prácticas colectivas. En resumen, desarrollar una cultura de la resistencia, una nueva forma de vivir que permita que el proceso revolucionario perdure y se potencie:

Al objeto de abrir un camino para la revolución, la insurrección debe ser preservada y consolidada en un proceso institucional. [... ] la revuelta se torna potente y duradera solo cuando inventa e institucionaliza un nuevo conjunto de costumbres y prácticas colectivas, es decir, una nueva forma de vida. [...] una gama de revueltas contemporáneas se ha visto consolidada en formas institucionales alternativas, como por ejemplo [...] el levantamiento zapatista de 1994 en México se desarrolló mediante la creación de asambleas autónomas, caracoles o estructuras de base de la comunidad, y juntas del buen gobierno. La clave consiste en descubrir en cada caso cómo (y hasta qué punto) el pro-

21 Texto extraído de la publicación ¡Rebelaos! (pág. 12). 
ceso institucional no niega la ruptura social creada por la revuelta, sino que la extiende y la desarrolla (Hardt y Negri, 2011: 356-357).

El proceso institucional no debe de repetir los errores cometidos en el pasado. Las nuevas instituciones han de hacer compatible el éxodo con la discusión interna del proceso. Estos nuevos espacios de encuentro y toma de decisiones han de concebirse abiertos al cambio. Este principio lleva a un dinamismo que permite transformar constantemente su forma y contenido. Todo puede ser modificado siempre y cuando sea promovido por las singularidades que lo componen y acordado por consenso en las diversas asambleas que tienen lugar en la CIC:

Las instituciones se basan en el conflicto, en el sentido en que extienden la ruptura social operada por la revuelta contra los poderes dominantes y al mismo tiempo están abiertas [...] en la medida en que son constantemente transformadas por las singularidades que la componen. [... [ Las instituciones concebidas de esta suerte son un componente necesario del proceso de insurrección y revolución (Hardt y Negri, 2011: 358).

El activista revolucionario que integra la CIC apuesta por una acción colectiva que entiende que puede llegar a ser constructiva e innovadora. Su resistencia tiene como campo de acción la producción biopolítica y dirige su actividad a la formación de espacios cooperativos y comunitarios. Para facilitar y potenciar este tipo de movilización la entidad juega en los márgenes de la ley.

Si adoptamos la visión de Hardt y Negri (2004: 117), la resistencia se da en tres niveles. En el primer nivel la CIC se sitúa dentro de las normas para neutralizar los efectos represivos de la ley ejerciendo e impulsando la desobediencia civil activa. Una acción colectiva dirigida a deslegitimar el dominio económico y político. No obstante, su incorporación a la red de resistencia global contra el neoliberalismo la situaría simultáneamente «dentro y fuera de la ley» al formar parte de un movimiento que desafía a las autoridades para generar un contrapoder. Este segundo nivel de resistencia llevaría a los activistas a ser solidarios ${ }^{22}$ con resistencias organizadas que quiebran el orden existente en un intento de construir espacios liberados (tercer nivel). La red distribuida les permitiría, en

22 La acción colectiva solidaria que la CIC desarrolla no implica una participación activa ni pertenecer o formar parte de estos grupos. Es una postura propia de una entidad que, en coherencia con su ideario, defiende o apoya una causa en principio ajena y se adhiere a la misma. 
teoría, atender estos tres niveles potenciando la democracia interna, y constituiría una estructura eficaz para hacer frente al poder.

Si tal y como comentó el subcomandante Galeano (EZLN) estamos viviendo un periodo que puede ser calificado como «cuarta guerra mundial», un estado que Hardt y Negri definen como «guerra civil imperial», entonces, resistirse al orden global que se apoya en la guerra, emprender acciones dirigidas a deslegitimar ese orden, representaría para los activistas de la CIC una tarea ética inexcusable. Entienden que frente a la violencia del dominio del capital, la respuesta adecuada es romper los vínculos con el poder político que la ampara y transitar hacia un nuevo mundo: la resistencia toma forma de éxodo. 


\section{Bibliografía}

Aínsa, F. (1999). La reconstrucción de la utopía. Buenos Aires: Ediciones del Sol.

Berger, P. (1969). El dosel sagrado. Buenos Aires: Amorrortu editores.

Calle, A. (2005). Nuevos movimientos sociales. Hacia la radicalidad democrática. Madrid: Popular.

Castells, M. (2013). La era de la información. Vol. 2. El poder de la identidad. Madrid: Alianza Editorial.

Geertz, C. (2011). La interpretación de las culturas. Barcelona: Gedisa.

González, R; Barranco, O. (2007). «Construyendo alternativas frente a la globalización neoliberal. Resistencias juveniles en Catalunya», Revista de estudios de juventud, núm. 76: 267-285.

Hannerz, U. (1998). Conexiones transnacionales. Cultura, gente, lugares. Madrid: Ediciones Cátedra.

Hardt, M.; Negri, A. (2002). Imperio. Barcelona: Paidós.

- (2004). Multitud. Barcelona: Debate.

- (2011). Common wealth. El proyecto de una revolución del común. Madrid: Akal.

IвÁñez, T. (2014). Anarquismo, neoanarquismo y postanarquismo. Barcelona: Virus editorial.

Iglesias, P. (2008). Multitud y acción colectiva postnacional. Un estudio comparado de los desobedientes: de Italia a Madrid (2000-2005). Tesis doctoral, Universidad Complutense de Madrid, Madrid.

Klandermans, B. (2001). «La construcción social de la protesta y los campos pluriorganizativos», en Laraña, E.; Gusfield, J. (eds.), Los nuevos movimientos sociales. De la ideología a la identidad. Madrid: CIS.

Lowy, M. (2004). «¿Hacia una nueva internacional?», en Sen, J.; Anand, A.; Escobar, A; Waterman, P. (eds.), El Foro Social Mundial: desafiando imperios. Barcelona: El viejo topo.

Retamal, C. (2007). «Ernst Bloch y la esperanza utópica de la modernidad», Pensamiento, 237:463-474. 


\section{Webgrafía}

Afinidad Rebelde [en línea]. ;Rebelaos! <http://enricduran.cat/wp-content/uploads/2013/02/04Publicacion_REBELAOS_Alta-Resolucion. pdf $>$ [Consultado: 7 de septiembre de 2016].

Candidatura de Unidad Popular [en línea]. «Qui som», <http://cup. cat/qui-som $>$ [Consultado: 8 de septiembre de 2016].

Grupo de Reflexión para la Autonomía [en línea]. «¿Reforma o revolución? Pensando la transformación social hoy - Acabar con el orden establecido». <http://www.grupreflexioautonomia.org/es/reforma-o-revolucion/ > [Consultado: 8 de septiembre de 2016].

INTEgRarevolucio [en línea]. «¿Qué entendemos por Revolución Integral?». $<$ http://integrarevolucio.net/es/revolucion-integral/que-entendemospor-revolucion-integral/> [Consultado: 7 de septiembre de 2016].

Movimiento de Resistencia Global [en línea]. «Manifiesto del Movimiento de Resistencia Global Madrid-Praga 2000»,<http://www.nodo50. org/praga00/manifiesto.htm $>$ [Consultado: 7 de septiembre de 2016]. 